\title{
Human Actions and Environmental Reactions: Deforestation in Gombe and Environs
}

\author{
Y. U. Ahmad ${ }^{1, *}$, Yahaya I. ${ }^{1}$, Bilkisu Y. Ahmed ${ }^{1}$ \\ ${ }^{l}$ Geography Department, Gombe State University, Gombe, Gombe State, (Nigeria)
}

*Corresponding Author: Y. U. Ahmad, Geography Department, Gombe State University, Gombe, Gombe State, Nigeria

\begin{abstract}
Deforestation refers to the depletion of three crown cover to less that $10 \%$ of its original state in any given area. When this happens, the damaging effect on the ecosystem can be enormous. The menace of deforestation in Gombe is the second major ecological problem after erosion that is threatening the area. This is so because majority of the populace resort to the utilization of woody biomass as a result of widespread poverty and also because of the over dependence on the sale of fuel wood as a means of livelihood. In addition the teeming population of the area depends on woodlands as their source of energy for cooking. As such hundreds of different tree species found in Dajin Akko and environs are completely cut down on a daily basis. The research discovered that over 35-40 loads of pick-up truck (locally known as Akori-kura) are being brought into the metropolis daily. The research focuses on the relationship between population increases due to state creation in 1996, and fuel wood price increase as a result of increased demand for fuel wood. The study shows that over 80-90\% of households rely on fuel wood for cooking leading to serious environmental problems such as: loss of biodiversity, dusty weather conditions, threats to cultural survival of the populace and deforestation. The paper recommends that the natural ecosystem must be safeguarded through the provision of alternative sources of energy for cooking which are affordable and easy to use so as to reduce pressure on the cutting of trees. Legislation against anti-environmental activities such as the cutting down of trees, should be made by the state house of assembly and enforced through the use of forest guards. Similarly environmental education should be embarked upon by the traditional/religious leaders, mass media and the state government to educate the populace on the dangers of deforestation and the importance of conserving natural vegetation. Gombe State Environmental Protection Agency (GOSEPA) should go beyond town cleaning to enable it capture other environmental variables, such as afforestation exercise.
\end{abstract}

Keywords: Human Actions, Environmental Reaction, Deforestation and Gombe Environs

\section{INTRODUCTION}

The problems of deforestation and environmental degradation in the broader sense have become international issues affecting almost every part of the world in one way or the other. Media reports, documentaries and scientific studies indicate that deforestation is an extensive environmental problem with local, regional and global consequences.

Barau (2004) asserts that "the human race is now engulfed in the dilemma between environment and development. Development generates environmental degradation, which annihilates mankind and his habitat".

Deforestation is today one of the most threatening ecological problems of the world. It is perhaps more serious in sub-saharan Africa where poverty is widespread as well as over dependence on fuel wood for financial gains and cooking are becoming higher. United Nation's Environmental Programme (UNEP) (1999:11) in Barau (2004) project states that:

"Between 1990 and 2020, species extinction caused primarily by deforestation may eliminate between 5-20\% of worlds species ... a potential loss of 15,000-50,000 species a year or about 40-140 a day".

However, it is believed as Olofin (1996) puts it that Man affects his environment as responds to the changing conditions to human manipulations, thereby creating a state of dynamic equilibrium that continues to adjust and re-adjust in space and time". 
Furthermore, studies have shown that worldwide woodland and forest resources are finite. Some experts use data on the world's fuel wood consumption to estimate how many years these supplies will last at the current and projected consumption rates. It is also important to note the consumption rates outstripped protection (afforestation). Therefore mankind eventually depletes them.

The issue of deforestation is very sensitive so much so that the Federal Government of Nigeria submitted a revised Report on the Combat of Desertification in the northern parts of the country. It has been estimated that between $50 \%$ and $75 \%$ of Bauchi, Borno, Gombe, Adamawa, Jigawa, Kano, Katsina, Kebbi Sokoto, Yobe, and Zamfara states in Nigeria are being affected by desertification. These states have a population of 35 million people accounting to about $35 \%$ of the country's total land area" Peter O. (2005) in Okaiyeto et al, (2005)

There is a fundamental difficulty in establishing accuracy in relation to the areas of forest and rate of forest loss due to information sources range, and out dated government statistics.

There is no doubt that the vegetation of Nigeria is being destroyed at a very fast rate. Considering that in the last few decades, it is possible to see that what was once an area of thick forest has been turned into an open area, Abaje (2007).

\section{HistoricAl OVERVIEW}

Deforestation begun in earnest in the $19^{\text {th }}$ century with the demand for ship timbers from British Navy which was based on the Freetown peninsula to control slave trade. Timber extraction began in 1816 with loggers working along the lines of penetration afforded by the rivers. By 1860 , however, lack of adequate wood supply supplied meant that the timber trade had dwindled is volume (Alison et'al 1995).

More so, many scholars have defined the term 'deforestation' in different ways. For example, Abaje (2007) defines deforestation as the 'deliberate destruction of vegetation as a result of the activities of man and his domesticated animals. Abaje (2007) further argue that these activities (of man) have altered the vegetation so much so that the climatic climax vegetation or natural vegetation hardly exists today'. Instead, what one finds include plagio-climate vegetation, secondary forest or re-growth forest vegetation, derived vegetation plantation of trees and cultivated lands.

Omejeh (2005) also argue that fuel wood is the major source of energy (in Nigeria) accounting for over $90 \%$ of the total energy used for domestic purposes in the country. Table 1 shows that gathering of fuel contribute to land degradation especially in agricultural regions with limited wooded areas.

Table1. Consumption of Fuel wood and other fuel alternatives in Nigeria

\begin{tabular}{|l|l|l|l|}
\hline S/n & Energy Type & Consumption Tones per Year & Annual Consumption Per Capita (Kg/Capital \\
\hline 1 & Fuel wood & $43,300,000$ & 161.18 \\
\hline 2 & Kerosene & $1,266,370$ & 13.49 \\
\hline 3 & $L P G$ & 66,046 & 0.79 \\
\hline 4 & Coal & 18,100 & 01.0 \\
\hline
\end{tabular}

Source: Energy Commission of Nigeria (1998) in Omejeh (2005).

\subsection{Alison (1995) Asserts That}

"The main problem in Africa at the present time is the loss of savanna woodlands in east, west and southern parts of Africa rather than humid tropical deforestation since some 11.5 million hectares were lost between 1980-1985. Nevertheless, the reduction in humid tropical forest areas In West Africa (Cameroon, Ghana, Guinea, Ivory Coast, Liberia and Nigeria) as well as Madagascar is a cause for concern".

In addition, Millington (1988) in Alison (1995) observed that: 'Detailed studies of deforestation in West Africa and Madagascar have shown that deforestation is as severe as in parts of Latin America and south East Asia'

'It is so pathetic that there is almost an entire disappearance or degradation of wood lands, and there replacement by savanna. It is generally agreed that forest and wood land are the only natural climaxes as far as roughly $15^{\circ}$ north of the equator. In addition, trees are being felled to provide space for crops to feed the rapidly rising populations and for profitable cash or export crops such as cocoa etc, Harrison (1977). 
Hence, the removal of natural vegetation followed by prolonged over-farming has impoverished many areas in Gombe and Akko axis.

Based on projections in table 2 below, that natural forests and plantations in Nigeria could sustainably supply about 76.6 million cube of wood with demand of 139.7 million cube, but deforestation will create a high wood supply shortage.

Also, Rapetto (1998) in Omejeh (2005) 'puts the rate of deforestation in Nigeria at about 300.000 hectares annually, and the rate at which the sahara desert is creeping southwards has been estimated to about $1 \mathrm{~km}(1000 \mathrm{~m})$ per year. Arnofor (1986) in Omejeh (2005) also recorded that afforestation rate is less than the rate of deforestation'

Table2. Projected wood class requirements (in “000m cube) for Nigeria (2000-2020)

\begin{tabular}{|l|l|l|l|l|l|l|}
\hline S/n & \multicolumn{1}{|c|}{ Wood Class } & \multicolumn{1}{|c|}{$\mathbf{2 0 0 0}$} & \multicolumn{1}{|c|}{$\mathbf{2 0 0 5}$} & \multicolumn{1}{|c|}{$\mathbf{2 0 1 0}$} & \multicolumn{1}{c|}{$\mathbf{2 0 1 5}$} & \multicolumn{1}{|c|}{$\mathbf{2 0 2 0}$} \\
\hline 1 & Fuel wood Charcoal & 84546 & 88833 & 93120 & 96822 & 1000524 \\
\hline 2 & Poles, piling \& post & 2210 & 2547 & 2883 & 3224 & 3764 \\
\hline 3 & Ply wood & 219 & 300 & 830 & 538 & 696 \\
\hline 4 & Swan wood & 3228 & 4310 & 5391 & 7413 & 9435 \\
\hline 5 & Particles board & 87 & 140 & 193 & 323 & 453 \\
\hline 6 & News print & 71 & 105 & 139 & 218 & 296 \\
\hline 7 & Printing \& writing paper & 8 & 13 & 18 & 29 & 40 \\
\hline 8 & Kraft \& paper board & 39 & 56 & 73 & 110 & 146 \\
\hline & Total & 90,408 & 96,304 & 102,197 & 108,777 & $1,015,354$ \\
\hline
\end{tabular}

Source: Forest Resources Study FORMECU in Omejeh (2005).

\subsection{The Study Area}

Gombe Metropolis is located between latitude $10^{\circ} 0{ }^{\prime} \mathrm{N}$ to $10^{\circ} 20^{\prime} \mathrm{N}$ and longitude $11^{\circ} 01^{\prime} \mathrm{E}$ and $11^{\circ}$ 19'E. It shares common boundaries with Akko LGA in the South and West; Yamaltu-Deba to the East and Kwami to the North. It occupies a total land area of about $40 \mathrm{Km}^{2}$.It is the capital of Gombe State, ( Aliyu 2002),

The pattern of population growth of Gombe town was slow from 1900 to 1952 (300 to 18,500 people) while; from 1964 to 1991 the population growth increased tremendously from 47,000 to 138,000. However, from the year 1996, when Gombe became the State capital, there was a noticeable sharp increase in population from169, 894 (1996) to 219,946 in 2000 (Tiffen, 2006) and 312,467 in the census 2006 and is projected to have reached about 400,000 in 2010 (NPC, 2006). This population explosion resulted in high demographic pressure on land and consequent developmental processes such as building of houses.

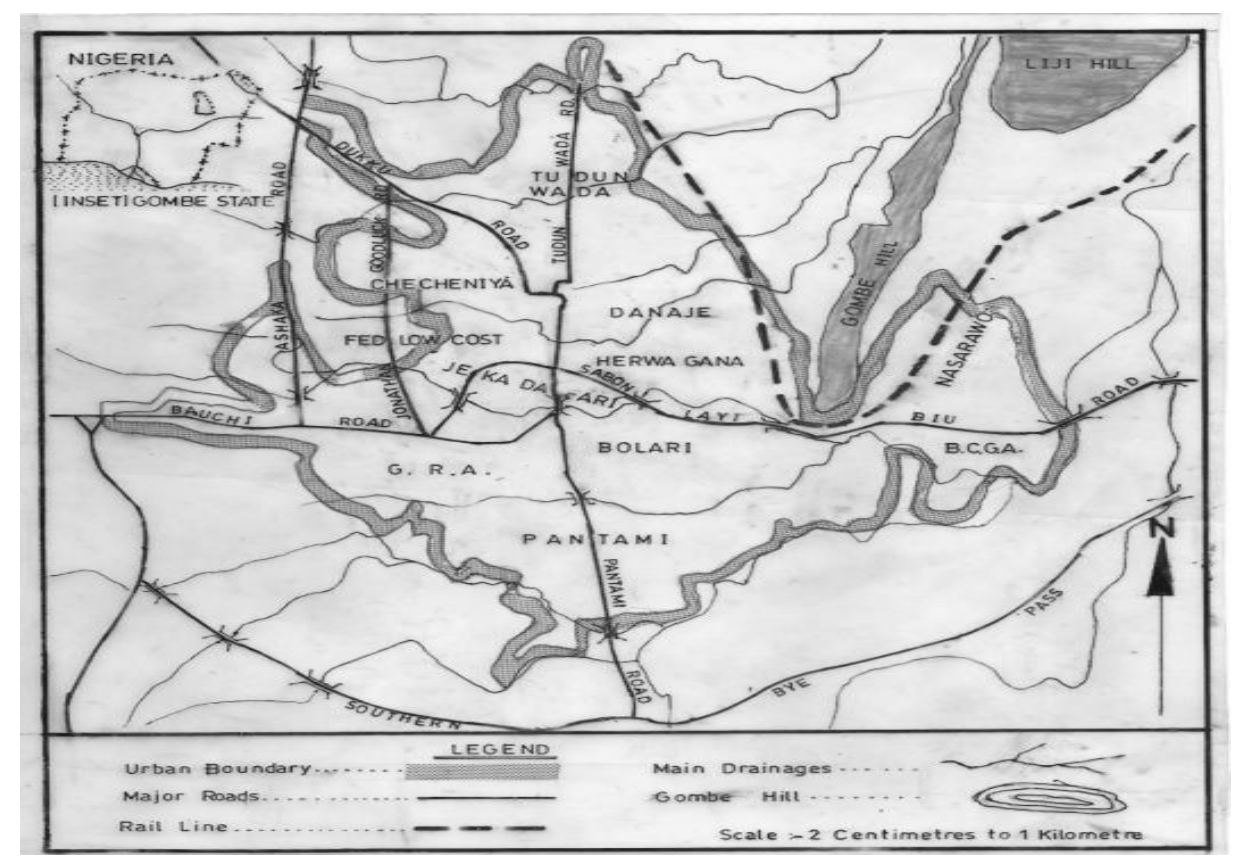

Figure1. An Overview of Gombe Metropolis 


\subsection{Material and Methods}

Basically the paper employs qualitative approach in order to have a close understanding of the targeted audience experience and perception on deforestation and fuel wood consumption in the study area. In essence, it is more about description of what has been found through face to face contact between the researchers and the subject of research. The paper also uses both primary and secondary source of data. In primary source of data, the study area was purposively divided into four (4) sampling units: Jeka-dafari, Shamaki/Tudunwada, Herwagana and Pantami/Gabukka where samples were drawn. In each 4 sample unit, 25 house-holds were selected using simple random sampling method and a total of 125 questionnaires were administered.

In-depth interviews (IDI) were also conducted with a cross section of fuel wood sellers in the two major fuel wood depots in the metropolis (i.e Tashan-Dukku in the north western part and Tashan Shongo in the south western part along Biu road). Also information was obtained that about 40 to 45 trucks of fuel wood were sold in the two markets on a daily basis, amounting to more than 1200 trucks in a month.

\section{RESUlt AND DisCUSSIONS}

\subsection{Level of Deforestation in the Study Area}

Trees are sustainable resources provided that those cut down are replaced, or there is sufficient time to allow natural regeneration to take place. In addition, to that, the importance of trees in an environment can never be overemphasized, as they aid in soil conservation, acts as wind breakers, climate modifiers (shade/canopy) fruits, animal feeds, construction materials, medicinal herbs and economic values, to mention but few.

The main source of energy in Gombe metropolis and environs is fuel wood which is consumed on a daily basis for cooking, heating and other purposes. This is the reality in the study area due to the rapid population growth, field study (2016). The population growth is however complemented with inadequate technology to develop or money to harness other alternative sources of energy such as gascookers, kerosene/electric cookers, etc.

In the area, the demand for fuel wood outstrips supply, and there is neither the chance to replant trees nor the time to allow for natural regeneration. Hence, the risk of deforestation in this part of the country expands at the rate of 1 kilometre per year, which has brought about irreversible damage to the environment. Research has shown that hundreds of tree species are completely cut down especially in the popular Dajin Akko. About 35-40 loads of pick-up are being conveyed into the urban Gombe daily (field study 2016).

Interviews conducted with cross-sections of wood -sellers revealed that the available fuel woods at commercial quantity are nearly exhausted in areas like Dajin Akko to the extent that they enchroach Dajin Alkaleri in Bauchi state.

More so, considering the increase in fuel prices in Gombe from (N30 to N60), especially from February, 2015 to the present time; one would be convinced that this increase in fuel price was brought about by the increase in demand due to the rapid population growth against the 'ready-made' fuel wood. The population growth is as a result of the creation of the state in 1996 coupled with the current security challenges of the Boko Haram insurgence in the north eastern part of the country which Gombe is part of (especially in Borno, Yobe and Adamawa) which added more pressure on the existing resources in the state, being 'relatively more peaceful' than the other surrounding states in the region.

Another fact is that, about $85-95 \%$ of the households rely solely on fuel wood as their main source of energy for cooking. Perhaps, other users such as bakery industries, suya meat sellers, etc also use wood fuel throughout the course of their production. These perhaps lead to the extinction of probably hundreds of plant species annually in spite of the fact that plants constitute an important part of the culture of a given society. It was also observed that certain trees based on their burning qualities attract more sellers and buyers than other trees. Eg (Afzelia Africana Kawo. Detarium senegalense Taura, Balanites aegyptica Aduwa, Ziziphus mauritiana Magarya, Aeschynomena indica Marke, e.t.c).This therefore makes them more preferable than the others, thereby leading to their depletion more than the other species. 

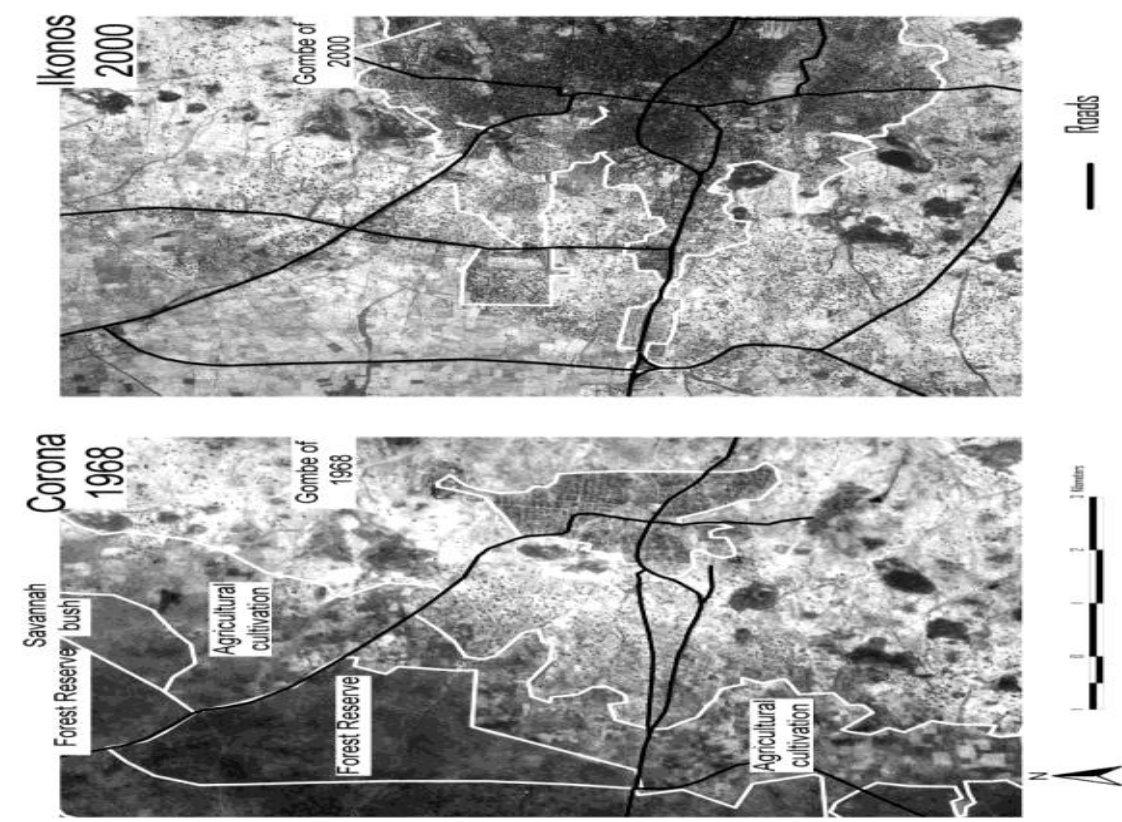

Figure2. Change of Agro-Forest Land use within the Catchment of the Gombe Gullies since 1968.

Source: Balzerek, et al (2013)

\subsection{Some Causes of Deforestation}

There are major ways in which the vegetation of Nigeria and that of Gombe in particular, can be altered in the following ways:

\subsubsection{Bush Burning}

This is the most common process of deforestation in the savanna region of Nigeria. Fires are often deliberately triggered off by some hunters, villagers and during farm clearing. Hunters also who search for game set fire in bushes which destroy natural vegetation.

\subsubsection{Cultivation}

Considering the fact that, people in this part of the country engage in farming, therefore farm lands are cleared and prepared for cultivation. Only economic trees, such as mangoes, locust beans etc are usually left. After, the ground has been cultivated for several years; it may become exhausted leading to a considerable decrease in number of tree, Abaje (2007). Furthermore, with increase in human population and therefore more pressure on land; the soils are not given enough time to recover, and the vegetation is therefore eliminated

\subsubsection{Fuel Wood Fossils}

Poverty has been identified as one of the key- factors facilitating deforestation visa-vis fuel consumption in the area. This is so because, a good number of youth and perhaps other middle aged people engage in tree cutting as a means of livelihood due to unemployment, (Field studies 2016).

\subsubsection{Urbanization}

Infrastructural developments such as building and constructions, roads constructions, reservoirs etc lead to serious loss in plants and animal communities. This could be clearly seen in construction of 'One Thousand Housing Estate' by Gombe State government in Shongo Idirisa as well as the rapid urbanization that tool place around Tumfure, Hammadu kafi, Riyad, Bomala where several kilometers square of land was taken away and most of the trees destroyed for residential purposes, (field studies 2009).

\subsubsection{Grazing}

Intense grazing in the savanna by domesticated animals contribute towards upsetting ecological balances, because there is much greater grazing pressures on certain species which are actively selected by animals. Hence, there will be decrease in the number of favored species and a consequent deterioration in the volume of the grazing lands. 


\subsection{Consequences of Deforestation}

Deforestation infringes the quality and beauty of the physical environment in the following way:

\subsubsection{Hydrological Consequences}

The removal or conversion of forests and wood lands to other land uses such as pastures or urbanization; involve significant disruptions to nutrient value cycle and indeed water balances.

Runoff processes are invariably affected by vegetation removal and ground surface disturbance. For example, under a wood land/forest canopy; soil infiltration rate is usually low. When the surface cover is removed, rain drops are allowed to impact directly on the soil, loosening fine soil particles and blocking soil pores. This as described by Alison et'al (1995) that loss of vegetation cover 'results in reduction in infiltration rates and increase in over-land flow erodibility and soil losses'.

\subsubsection{Climatological Consequences}

It has been recognized for some times, Smic (1971) in Alison et'al (1995) “...that deforestation is responsible for important changes in heat balances, water budgets and ecological balances on a variety of scales".

Deforestation affects a significant range of interrelated climatic elements on the earth's surface, namely:

- Aerodynamic roughness

- Albedo

- Net radiation/temperature and

- Energy balance transfer (i.e partitioning of net radiation into sensible and latent heat fluxes) which modifies atmospheric circulation system.

\subsubsection{Health Consequences}

Gratz (1997) in Omejeh (2005) observes that tropical diseases such as malaria, filariasis leshmaniasis, and cholera and Hemorrhagic fever are often as a result of deforestation. This is because the removal of vegetation gives rise to stagnant bodies of water where mosquito can breed easily. Some animal species such as birds and lizards disappear, making insect population swell thereby facilitating transmission of diseases"

'However, if desertification follows the desertification, then they associated increase in surface albedo $(0.24)$ can seriously disrupt the regional radiation balance. The surface decrease following the increased solar radiation reflection which cools the atmosphere with increased anticyclonic subsidence and reduced free conviction leading to reduce precipitation'. Kemp (1990) in Omejeh (2005).

\subsection{Deforestation: The Way Forward}

The widespread global concerns over tropical deforestation; have resulted in public pressure on governments and policy-makers to tackle the issues that led to this unacceptable rape of forests. Such pressure has resulted in a number of recent initiatives to halt deforestation.

It is also important to note that the proper utilization, management and protection of environment is a collective responsibility as contained in the communiqué of the fifteen years discussion on Global Agreement Adopted to Protect World Forests which states that:

"We have only one planet to share; all must ensure its health and sustainability, because the livelihood of over a billion of world's poor is at stake" Barau (2004).

The need to maintain the quality of our environment for the sake of future generations is necessary to achieve that, the following steps should to be taken:

\subsection{Environmental Education}

Environmental education both Informal and formal types of environmental education should be stressed. 
The former is learnt at home and continues in the other aspects of life. It is not necessarily taught in the classroom. It may include the attitudes of parents towards their children in relation to the environment. Although, other means are through public enlightenment via TV and radio programs, pamphlets, news papers, magazines, etc.

While, informal environmental education, involves the teaching of environmental problems in various educational institutions - as the name implies- starting from nursery schools up to the institutions of higher learning. In this case, details about the environmental degradations/problems, management, amelioration and sustainable development should be properly taught.

To control deforestation and promote a afforestation; indiscriminate cutting down of trees for different purposes should be regulated in order to maintain the quality of physical environment and its variables and indeed perpetuate the existence of various plant and animal species. This perhaps is encouraged even in the religio-cultural provisions that these resources (water, soil vegetation, minerals and atmosphere) are exhaustible; as such man has not been given a license to inappropriately utilize them.

It is in line with this that elites and traditional rulers should embark and imbibe the culture of planting trees and encourage civil servants and community members and other individuals to do so in order to improve the quality of the environment.

Gombe State University has given a good example of how environmental regeneration should be carried out through its activities of one person, one tree. The tree campaign exercise involved the State Governor, important personalities, University Management and members of staff, where seedlings were planted within and outside the University. The 2004-2006 Gombe State University's annual report (page 21) states:

"Accordingly, Gombe State University should be in the forefront, among other things, in promoting practical general environmental protection, improvement and conservation through the planting of trees, and horticultural activities from both students and the community in which the university is located can copy and benefit".

\section{Conclusion}

Deforestation is not simply a recent phenomenon, and the history of deforestation represents an important avenue of study if we are to understand the cause and consequences of the savanna woodlands deforestation. Notwithstanding this, deforestation rates are currently higher in Gombe and environs than what was obtained in the past.

However, one can conclude that deforestation is a product of economic crises and population pressure on the vegetation resources of the area. In addition to that, the risk of deforestation (which expands at the rate of about $1 \mathrm{~km}$ per year in the northern part of the country at the rate of 1000 meters per annum according to some studies) cause irreversible damage to the environment thereby leading to desert encroachment if the needed attention is not yet given.

\section{RECOMMENDATIONS}

- Economic and social development are essential for ensuring a favorable living and working environment for man and for creating conditions on earth that is necessary for improvement of the quality of life. This could be achieved through economic empowerment and provision of other alternative sources of energy (such as nuclear, solar, kerosene and electric cookers etc) at cheaper rates and affordable rate to divert people from over dependence on fuel wood consumption which is environmentally -friendly. 'As global energy consumption grows each year, development of certain alternative energy source becomes increasingly important.

- Education in environment matters for younger generations as well as adults giving due considerations to underprivileged; is essential in order to broaden the bases for an enlightened opinion and responsible conduct by individuals, enterprises and communities in projecting and improving the environment in its full human dimension. It is also essential that massmedia be fully involved in public re-orientation towards conserving natural vegetation in all respect.

- Legislation also should be re-enforced to curtail unnecessary bush burning and tree cutting. This can be done successfully through the use of forest guards. 
- Gombe State Government should also intensify its efforts towards encouraging individuals, NGO'S and communities to participate in viable afforestation and re-forestation programmes through provision of free seedlings and other physical efforts. The planted trees need continuous monitoring.

- Finally, Gombe State Environmental Protection Agency (GOSEPA) should go beyond town cleaning, by doing so, its responsibilities should be reviewed in order to enable it capture other environmental variables as the name implies. Such variables may include tree planting/nursing, landscaping, etc.

\section{REFERENCES}

[1] Abaje I. B (2007): Introduction to Soil and Vegetation. Kaduna, Nigeria. Alison J. et'al (1995): Humid Tropical Environment

[2] Annual Report (2002-2006): Gombe State University, Gombe. (Page: 21).

[3] Aliyu, D. (2002). A comparative Study of Soil Fertility Status Under Different Agricultural Practice in Gombe Local Government Area. An unpublished B.Sc. Dissertation, Geography Department Bayero University Kano, Nigeria.

[4] Barau S.A, (2004): Environment and Sustainable Development in the Qur'an IIIT, Kano- Nigeria.

[5] Harrison R. J, (1977): West Africa: A study of Environment and Man's Use of it.

[6] Hodges L, (1975): Environmental Pollution: A Study Emphasizing Physical and Chemical Principles.

[7] NPC: (1991 and 2006) Census Results. National population commission, Gombe office

[8] Olofin E.A, (1996) A Paper on the: Geography and Environmental Monitoring for Effective Resource Management.

[9] Omejeh J.E, (2005): A Review of Deforestation and Extension Efforts in Adamawa State, Nigeria. Savanna Journal, ABU, Zaria. Volume 20 No1 June, 2005.

[10] Tiffen, M.(2006) Gombe Emirate, 1900-68: Urban and commercial development. A public lecture held in Gombe State University $12^{\text {th }}$ February.

[11] Okaiyeto O. P and Lamidi O.S (2005): A Note on Forest Regeneration and Afforestation in the Northern Nigeria. Savanna Journal, ABU, Zaria Volume 20 No.1. June, 2005.

Citation: Y. U. Ahmad, Yahaya I., Bilkisu Y. Ahmed. "Human Actions and Environmental Reactions: Deforestation in Gombe and Environs". International Journal of Research in Geography. vol 4, no. 1, 2018, pp. 37-44. doi:http://dx.doi.org/ 10.20431/2454-8685.0401006.

Copyright: () 2018 Authors. This is an open-access article distributed under the terms of the Creative Commons Attribution License, which permits unrestricted use, distribution, and reproduction in any medium, provided the original author and source are credited. 